\title{
¿Régimen jurídico unitario para las concesiones o pluralidad de regímenes especiales? (*)
}

\author{
Francisco López Menudo \\ Catedrático de Derecho Administrativo \\ Universidad de Sevilla
}

\begin{abstract}
SUMARIO: I. LA UNIFICACIÓN DE LA FIGURA DE LA CONCESIÓN. UNA LÓGICA ASPIRACIÓN ENVUELTA EN DIFICULTADES. II. EL CONDICIONANTE "VERTICAL", INHERENTE AL REPARTO COMPETENCIAL ESTADOCOMUNIDADES AUTÓNOMAS EN MATERIA DE CONTRATOS Y CONCESIONES. A. LA LEGISLACIÓN ESTATAL GENERAL SOBRE CONTRATOS ADMINISTRATIVOS. 1. La dicotomía "básico-no básico" en la regulación del contrato de gestión de servicios públicos. Inventario y crítica. 2. El régimen del contrato de concesión de obras públicas: entre el uniformismo "vertical" y la disgregación "horizontal". B. LA LEGISLACIÓN AUTONÓMICA. 1. Legislación general de desarrollo de las bases estatales. 2. La legislación sectorial reguladora de los distintos servicios públicos. III. EL CONDICIONANTE "HORIZONTAL", DERIVADO DE LA DIVERSIDAD DE TIPOS CONCESIONALES. A. EL DOBLE EFECTO DISGREGADOR-UNIFICADOR DEL NUEVO RÉGIMEN DEL CONTRATO DE CONCESIÓN DE OBRAS PÚBLICAS. B. LAS LEYES ESPECIALES QUE REGULAN SERVICIOS PÚBLICOS CONCRETOS. ¿ES ANÓMALA ESTA DIVERSIDAD? C. ¿ES FACTIBLE UN RÉGIMEN UNIFICADO PARA LA CONCESIÓN DEMANIAL Y LA DE SERVICIO PÚBLICO? IV. UNA PREMISA FUNDAMENTAL: QUÉ DEBA ENTENDERSE POR “RÉGIMEN JURÍDICO GLOBAL”.
\end{abstract}

\section{LA UNIFICACIÓN DE LA FIGURA DE LA CONCESIÓN, UNA LÓGICA ASPIRACIÓN ENVUELTA EN DIFICULTADES}

La pregunta que plantea el título de esta Ponencia tiene mucho sentido; siempre lo ha tenido y quizás siempre lo tenga en el futuro pues es de suponer que siempre existirán servicios públicos. A la pregunta en cuestión acaso

\footnotetext{
* Texto de la Ponencia española titulada "Regime jurídico global ou pluralidade de regimes especiais para as concessões" que fue presentada en el VI Congreso luso-español de Derecho Administrativo, celebrado en Lisboa los días 3 y 4 de diciembre de 2004, dedicado a "As concessões em Direito Público". La presente Ponencia cerraba la serie de cinco que fueron dedicadas a diversos aspectos del régimen de la concesión de servicios públicos. Hasta la fecha no han sido publicadas las Actas de dicho Congreso razón por la que publicamos aquí la Ponencia, respetando en su integridad el texto presentado en su día a la Comisión organizadora.
} 
sea fácil darle una respuesta inmediata; pero resulta complicado justificar cumplidamente tal respuesta en el espacio ahora disponible. En cualquier caso la propia índole de la pregunta conduce al examen del derecho interno. Su alusión a un "régimen jurídico global" no será conectada aquí con el Derecho comunitario, conexión que ya han realizado otros ponentes en este Coloquio. Por consiguiente, la cuestión de si resulta factible o no construir un régimen jurídico global para las concesiones será aquí examinada desde la exclusiva perspectiva del Derecho administrativo español interno.

En verdad, sería pertinente formular la misma pregunta en relación con cualquier campo del Derecho Administrativo actual, malherido como está de los golpes que le propina el legislador, sin duda preocupado por dar a luz las muchas disposiciones que son hoy necesarias para afrontar los retos de un mundo tan acelerado, pero absolutamente despreocupado por paliar, con un mayor esmero en el arte de legislar, los inconvenientes de ese imperativo fatal. El Derecho Administrativo de los últimos tiempos es el condensado de un universo de fragmentos, de retales que se sobreponen como parches unos sobre otros. Con ser esto malo, lo peor es que estos remiendos aparecen con harta frecuencia desubicados de las materias que les son propias, todo lo cual conduce a la confusión y a la destrucción de la certeza del Derecho. No será extraño encontrar normas urbanísticas en la legislación de patrimonio, o normas sobre patrimonio en la legislación de la organización, o normas de organización en la legislación de medio ambiente.

La agitada historia de la legislación sobre contratos en los últimos años da buena prueba de lo que decimos. Bastaría recordar las numerosas reformas sufridas por la Ley de Contratos de 1995, y cómo una de ellas fue introducida por una Ley -9/1996, de 15 de enero- cuyo objeto era la adopción de "medidas extraordinarias, excepcionales y urgentes como consecuencia de la persistencia de la sequía”. En suma, un mundo normativo donde casi nada es jurídicamente seguro en el sentido técnico de la expresión y donde el jurista, más que un pensador, queda convertido en una especie de coleccionista buscador de normas en angustiosas bases de datos -algo así como el triste Don José del "Todos los nombres" de Saramago-, dilapidando sus energías sólo en tratar de determinar cuál sea el derecho aplicable en cada caso.

Si esto es así en general, con mucha más razón, o sinrazón, ocurre en el campo de las concesiones administrativas, dado el papel central de la figura y su altísima implicación en tantas actividades públicas de las que son titulares las Administraciones territoriales e institucionales, e incluso sujetos de naturaleza privada, todos ellos -actividades y sujetos- regidos por un sinfín de re- 
gulaciones particulares que terminan incidiendo o modulando en mayor o menor medida la figura de la concesión.

La pregunta de si es factible o no un régimen global o unitario de la concesión no es nueva ${ }^{1}$. Es más, antes que nada nos mueve a la reflexión de si estas preocupaciones de tipo dogmático o estructural son cosa exclusivamente de científicos o profesores, necesitados de captar las instituciones al completo y de comprenderlas por entero para poder explicarlas al público o escribir sobre ellas; preocupaciones muy distintas a las de un juez, o del responsable de una empresa o del titular de un órgano administrativo gestor de un tipo concesional determinado. Ciertamente, cuando se observa el panorama se siente el deseo de huir de todo intento de sistematización, pues como ha señalado el profesor MARTÍNEZ LÓPEZ-MUÑIZ, lo primero que hay que hacer es ponerse de acuerdo para saber de qué hablamos en cada momento cuando nos referimos al concepto de servicio público... Y lo segundo -añadiríamos por nuestra parte- sería ponernos también de acuerdo sobre qué debamos entender por un "régimen jurídico global", repregunta esta que se abordará más adelante.

Pero como ocurre con todos los temas clave no cabe zanjarlos sin más pues como siempre ocurren cosas nuevas que les afectan, siempre exigen ser estudiados de nuevo. Así ocurre con el tema de la concesión. La figura se ha dispersado de un modo espectacular, tanto en sentido vertical, con la aparición de las Comunidades Autónomas y la multiplicidad de servicios públicos que gestionan, como en sentido horizontal, dadas las numerosas leyes especiales existentes y la utilización instrumental de las normas contractuales para otras actividades que no son genuinos servicios públicos; o acaso también lo sean, si el concepto de servicio público se interpreta en un sentido objetivo.

El diagnóstico del momento presente puede encontrarse en palabras de la propia Ley 13/2003 de 23 de mayo, reguladora del contrato de concesión

\footnotetext{
${ }^{1}$ Me permito traer a colación una Sentencia del Tribunal Supremo de 11 de junio de 1979, escrita con la siempre brillante pluma de D. Ángel Martín del Burgo y Marchán, que curiosamente hacía unas excursiones sobre este tema tan teórico; decía que "en el mundo del derecho, cuanto más importantes son las instituciones, más controvertidas suelen ser en el plano doctrinal”, afirmando de la concesión, de su naturaleza jurídica, que es un tema en el que todo se cuestiona, "desde si es posible una construcción unitaria de la misma, o, por el contrario, sólo pueden darse notas comunes de sus distintas especies...", ... aunque con ingenio eludía finalmente dar respuesta a estas meditaciones afirmando que lo mejor era superar estas elucubraciones y atenerse a las circunstancias del caso concreto que tenía a la vista. Solución ciertamente prudente, y desde luego práctica, dado que se trataba tan sólo de resolver un asunto dictando una sentencia.
} 
de obras públicas cuya Exposición de Motivos viene a destacar "tanto la vigencia de la concesión como su regulación singular y fragmentada, impuesta por su necesaria adaptación a los objetivos diferenciados a los que sirve en el marco de las legislaciones sectoriales", añadiendo que "este tratamiento diversificado ha llegado a oscurecer su concepto e incluso a violentar sus notas sustantivas a favor de soluciones muy concretas hasta hacer perder, paradójicamente, a la institución, víctima de este afán de especialización, gran parte de su capacidad ordenadora". Un buen diagnóstico por cierto, aunque cabría preguntar a ese mismo legislador de la Ley 13/2003, si él mismo puso todo de su parte para evitar los vicios que denuncia, pregunta esta que tiene una fácil respuesta, desde luego negativa.

Creemos que, sea por unas causas o por otras, siempre se mantendrá viva la aspiración, por no decir ilusión, de hacer de la concesión una institución unitaria. Sin duda que este debate será el perpetuo sino de esta figura, dada su posición central en el sistema y su enorme valor histórico y conceptual. Siempre contrariará al jurista, tan huérfano como está de referencias seguras, que una figura de tanto peso específico como la concesión se encuentre tan dispersa en vez de estar codificada, es decir, constituida como merecería, como una categoría jurídica de rasgos ciertos y seguros, de absoluto valor resolutorio. Pero nos encontramos ante la evidencia de que la concesión ha de reflejar el modo de ser de actividades y servicios muy heterogéneos entre sí, y que son muy débiles las teóricas barreras que separan las concesiones de servicios de otras figuras aledañas, llámense autorizaciones o concesiones demaniales, todo lo cual viene a difuminar la pretendida nitidez de la figura de la concesión.

Hace ya algunos años, el profesor VILLAR PALASÍ, en un célebre estudio $^{2}$, afirmaba la abstracta posibilidad de construir el concepto de la concesión administrativa sobre una base común que acogiese elementos que prima facie pueden parecer diversos e incompatibles; y daba cuenta de algunas ideas-fuerza utilizadas a tal efecto por la doctrina de cada momento y lugar, relativizaba el valor de los criterios clásicos al uso para distinguir la concesión de la autorización administrativa y ofrecía su propia tesis personal de que el nexo que puede aglutinar la figura de la concesión, sean estas demaniales o de servicio público, sean constitutivas o traslativas, se encuentra en la cláusula "salvo iure tertii". Pero no seguiremos aquí por esos caminos dialécticos porque el problema que ahora unos ocupa, no es el de averiguar la naturaleza jurídica de los distintos tipos concesionales con el fin de acuñar un posible concepto uni-

2 "La eficacia de la concesión y la cláusula "sin perjuicio de tercero", $R A P$, núm. 5, págs. 147 y ss. 
tario válido para todos ellos. No estamos ante una preocupación dogmática sino ante la reflexión, mucho más simple y puramente práctica, de si deben estar dispersas regulaciones que quizás pudieran fundirse en pro de la economía y la seguridad jurídica.

Puestos a hacer una evaluación de las posibilidades que tendría en la actualidad una regulación unitaria de la concesión han de tenerse en cuenta los dos conjuntos de elementos o ingredientes que concurren en el problema. Estos son los naipes a barajar:

$1^{\circ}$ ) de una parte, la variedad de las medidas legislativas (legales y reglamentarias, generales y especiales; comunes y particulares; abstractas y sectoriales; estatales, autonómicas y locales) que concurren o pueden concurrir en la conformación del régimen jurídico de un servicio público concreto o actividad asimilada. Sobre esta nutrida panoplia de disposiciones de distinta naturaleza y rango que pueden intervenir en la configuración del régimen de un determinado servicio público en sentido estricto, debemos tener en cuenta las siguientes:

a) Para los contratos típicos de gestión de servicios públicos o de concesión de obras públicas, la totalidad de los preceptos de la LCAP y de su Reglamento Ejecutivo ${ }^{3}$, si el sujeto contratante es la Administración General del Estado o sus Organismos Públicos. Si se trata de las Comunidades Autónomas, sólo los preceptos que estén calificados como básicos.

b) Si se trata de contratos administrativos especiales habrá que estar en primer lugar a lo que dispongan esas normas especiales. En estos casos habrá que tener en cuenta las reglas del reparto competencial sobre la actividad de que se trate.

c) Las disposiciones que pueda haber dictado la Comunidad Autónoma en ejercicio de su competencia de desarrollo legislativo y ejecución de las bases estatales. Y las normas que pueda emitir para regular los aspectos que no son básicos.

d) Las leyes o reglamentos que disciplinen el servicio mismo -también teniendo en cuenta el reparto de competencias entre el Estado, las Comunida-

\footnotetext{
${ }^{3}$ Real Decreto 1098/2001 de 12 de octubre. Aprueba el Reglamento General del la Ley de Contratos de las Administraciones Públicas.
} 
des Autónomas y los Entes Locales-, que constituirán la fuente principal de definición de los derechos y deberes de las partes que se incorporarán al propio contrato, amen de otras particularidades relativas al poder de dirección, inspección y control, causas de extinción o de resolución, etc.

e) Los Pliegos de Cláusulas generales o particulares que puedan haber dictado las Administraciones competentes ratione materiae.

$2^{\circ}$ ) de otra parte, las distintas figuras o negocios, o situaciones y relaciones jurídicas, que en mayor o menor medida se sirven de las reglas previstas para la concesión de servicios públicos; una gama ésta que va desde aquellas situaciones en que la Administración asume un intenso protagonismo desde la gestación hasta el fin de la vida de la concesión, velando por su buena gestión y la satisfacción del interés público en juego, fines para los cuales están precisamente diseñadas las normas que componen el régimen de la concesión de servicio público; hasta aquellos otros negocios o "status" que aunque con figura de concesión como forma de otorgamiento del título, es considerablemente menor el interés de la Administración en el buen fin del negocio y menor también su celo en la vigilancia de la gestión. En suma, actividades en las que se encuentran implicados objetivos o intereses de carácter público pero que no son genuinos servicios públicos en el sentido clásico de la expresión.

Ese mero interés, distinto al que es propio de un genuino servicio público, puede quedar circunscrito y agotarse en el simple objetivo de conseguir, a través de la concesión como instrumento, ora garantizar la transparencia, la igualdad y la neutralidad en el otorgamiento de los títulos, mediante la utilización de las normas que ya tienen regulada la publicidad y la concurrencia (p.ej. concesión para el comercio al por menor del mercado de tabacos); ora para gobernar un sector de actividad excluido del libre mercado, es decir, reservado al sector público (p. ej. concesión de loterías y juegos de azar ${ }^{4}$ ); o bien para organizar el ejercicio de actividades privadas en principio libres pero necesariamente sujetas a cupos o limitaciones en cuanto a su número (así, los llamados "servicios particulares destinados al público" cuando adoptan la forma de concesión $)^{5}$; o bien para imponer a esas actividades libres eventuales obli-

\footnotetext{
${ }^{4}$ Vid. al respecto interesantes SSTS 11 diciembre 1998 y 30 enero 1999 (Ar. 10366 y 1694).

${ }^{5}$ Por ejemplo, concesión de kioscos, hamacas, instalaciones deportivas, supermercados en zonas portuarias, etc. Es controvertido en estos casos si los títulos son realmente concesionales o autorizatorios. Vid. SSTS de 17 junio 1987 (Ar. 6499), 15 junio 1988 (Ar. 4606), 20 diciembre 1999 (Ar. 8787).
} 
gaciones de servicio público, como ocurre en el sector de las telecomunicaciones $^{6}$ y demás sectores liberalizados. Podrá ser discutible si estos sectores liberalizados producen o no la "fuga" del concepto de servicio público; pero no es discutible que han venido a encoger la figura de la concesión, haciéndola más unitaria que antes. En suma, actividades en las que se encuentran implicados objetivos o intereses de carácter público pero que no son genuinos servicios públicos. También servirá la concesión como "instrumento escoba", o sea, para que la Administración reasuma actividades liberalizadas que le retornan o vienen de rebote, sencillamente porque el mercado no las quiere y las devuelve.

En todos estos casos se hará un uso parcial, nunca total, de las normas que componen el contrato de gestión de servicio público. Unas veces se utilizarán sus reglas adjetivas, referidas a la preparación y adjudicación de los contratos; otras veces se utilizarán sólo algunas de sus reglas sustantivas que disciplinan la vida del contrato, los derechos y deberes del empresario y las prerrogativas de la Administración. Pero cualquiera que sea la clase o cantidad de preceptos que se extraigan del régimen de la concesión de servicios públicos para su aplicación a otros supuestos -sean éstos servicios públicos o no- lo cierto es que las normas concebidas para regular la concesión de servicios públicos se constituyen así en una especie de banco o fondo normativo no para disciplinar una concreta actividad o servicio sino para suministrar principios, reglas, soluciones, tanto adjetivas como sustantivas, al servicio de objetos y fines muy diversos, incluso ajenos en algún caso a la propia idea concesional.

\footnotetext{
${ }^{6}$ Vid. Ley 23/2003 de 3 de noviembre de Telecomunicaciones. Este mercado está totalmente liberalizado, regido por la libre competencia y no precisa de autorizaciones o licencias. No obstante, la Ley contempla la posibilidad de imponer obligaciones de servicio público, tanto de servicio universal como otras obligaciones por razones de interés general. Su artículo 23.2 contempla el sistema de designación de operadores encargados de garantizar la prestación de los servicios con sujeción a los principios de eficacia, objetividad, transparencia y no discriminación. En todo caso se contemplará un mecanismo de licitación pública para todos o algunos de dichos servicios, prestaciones y ofertas, que deberá utilizarse cuando de un proceso de consulta pública resulte que varios operadores están interesados en ser designados para garantizar la prestación del servicio universal en una zona geográfica determinada, con carácter exclusivo o en competencia con otros operadores. Por tanto, hay que observar que la Ley conecta con la regulación del contrato de gestión de servicio público por dos vías: por la relativa a la licitación y también por las regulaciones de fondo ya que el artículo 20 señala que "Los operadores se sujetarán al régimen de obligaciones de servicio público y de carácter público de acuerdo con lo establecido en este título, y que se aplicará con carácter supletorio el régimen establecido para la concesión de servicio público determinado por el Texto Refundido de la Ley de Contratos de las Administraciones Públicas".
} 
Ese banco o fondo normativo suministrador de reglas está constituido por dos piezas fundamentales de nuestro derecho administrativo contractual: el cuerpo de preceptos del Texto Refundido de la Ley de Contratos de las Administraciones Públicas (en adelante, LCAP) ${ }^{7}$ que componen el régimen del contrato de gestión de servicios públicos; y el cuerpo de preceptos que configuran el contrato de concesión de obras públicas.

Queda, pues, descrito, grosso modo, el abigarrado conjunto de elementos a conjugar a la hora de plantearse la posibilidad o no de una unificación del régimen jurídico de la concesión. Como puede verse, una tal operación tendría que enfrentarse y superar dos órdenes de obstáculos que situamos en dos coordenadas básicas: una vertical -de una clara implicación política o constitucional- que tiene que ver con el Estado de las autonomías, es decir, la disolución del antiguo monopolio del Estado para dictar normas contractuales válidas para todas las Administraciones Públicas; y otra horizontal -de una dimensión meramente técnica-, ligada al hecho de que no hay dos servicios públicos iguales, de que existen leyes especiales que los regulan, y de que también existen actividades que aun no siendo de servicio público se sirven sin embargo de elementos de la concesión de servicios porque su respectiva normativa se remite a determinados artículos o partes del régimen del contrato de gestión de servicios públicos contemplado en la LCAP. Tal ocurre con las concesiones de dominio público, las llamadas concesiones industriales, la explotación de bienes o actividades monopolizados, etc.). Valga la reiteración: la coordenada vertical tiene una dimensión política o constitucional, mientras que la horizontal tiene una dimensión puramente técnica.

Es preciso despejar otra cuestión previa de importancia decisiva para la cuestión que nos ocupa. Hay que volver a la pregunta que va en el rótulo de esta Ponencia y determinar a qué nos estamos refiriendo cuando hablamos de "unificación" o de "régimen global", pues técnicamente sería posible diseñar distintos modelos que pudiéramos llamar por igual "unificadores" y que sin embargo tendrían cada uno de ellos un contenido y un alcance muy distinto. Pero veamos esto más adelante y examinemos a continuación con algún detalle el estado de la cuestión en cada una de las dos coordenadas antes referidas.

\footnotetext{
${ }^{7}$ Real Decreto Legislativo 2/2000 de 16 de junio, modificado, en lo que aquí nos interesa, por la Ley 13/2003 de 26 de mayo, reguladora del contrato de concesión de obras públicas.
} 


\section{EL CONDICIONANTE "VERTICAL", INHERENTE AL REPARTO COMPETENCIAL ESTADO-COMUNIDADES AUTÓNOMAS EN MATERIA DE CONTRATOS Y CONCESIONES}

El primer factor que vendría a dificultar o interferir el propósito de una unificación legislativa del régimen de la concesión sería la centrifugación que es propia del Estado de las Autonomías y el consiguiente reparto competencial tanto sobre la rúbrica "contratos y concesiones administrativas" (art. 149.1.18 $\mathrm{CE}$ ), como sobre los distintos sectores materiales -que puedan albergar actividades de servicio público- enumerados en el propio artículo 149 y en los Estatutos.

Comoquiera que corresponde al Estado la competencia exclusiva para dictar las bases en materia de contratos y concesiones administrativas, ello quiere decir que le compete establecer "un común denominador normativo dirigido a asegurar, de manera unitaria y en condiciones de igualdad, los intereses generales a partir del cual pueda cada Comunidad Autónoma, en defensa de sus propios intereses, introducir las peculiaridades que estime convenientes y oportunas, dentro del marco competencial que en la materia le asigne su Estatuto". Respecto a los contratos administrativos es obligado citar la STC 141/1993 de 22 de abril ${ }^{8}$ en la que se declara que "la normativa básica en materia de contratación administrativa tiene principalmente por objeto, aparte de otros fines de interés general, proporcionar las garantías de publicidad, igualdad, libre concurrencia y seguridad jurídica que aseguren a los ciudadanos un tratamiento común por parte de todas las Administraciones Públicas". Ello quiere decir que todas las normas que tiendan directamente "a dotar de efectividad práctica a aquellos principios básicos de la contratación administrativa deben ser razonablemente considerados como normas básicas" mientras que "no lo serán aquellas otras prescripciones de detalle o de procedimiento que, sin merma de la eficacia de tales principios básicos, pudieran ser sustituidas por otras regulaciones asimismo complementarias o de detalle, elaboradas por las Comunidades Autónomas con competencia para ello". Análoga doctrina es aplicable a las concesiones administrativas ${ }^{9}$.

\footnotetext{
${ }^{8}$ Resuelve el conflicto positivo de competencia planteado por el Gobierno Vasco contra el RD 258/1986 de modificación del Reglamento General de Contratación del Estado.

${ }^{9}$ En efecto, con base en la doctrina señalada el Tribunal legitima la regulación efectuada por el Estado de determinadas concesiones, tanto de servicio público (S. 118/1996, de 27 de junio) como de dominio público (SS. 227/1988, de 29 de noviembre, 193/1998, de 1 de octubre, o 149/1991, de 24 de julio).
} 
Esas previsiones constitucionales se encuentran materializadas en el Texto Refundido de la LCAP de 2002, actualizado por la Ley 62/2003 que adicionó al ya preexistente y tradicional contrato de gestión de servicios públicos -que llamaremos "ordinario"- el nuevo régimen del contrato de concesión de obras públicas. Los analizaremos por separado.

\section{A. LA LEGISLACIÓN ESTATAL GENERAL SOBRE CONTRATOS ADMINISTRATIVOS}

1. La dicotomía "básico-no básico" en la regulación del contrato de gestión de servicios públicos. Inventario y crítica

Sería muy ilustrativo exponer con detalle el inventario de los preceptos contenidos en el tronco común, es decir la "fotografía en positivo" del régimen contractual básico estatal. Pero hay que desistir de la idea por razones obvias de espacio y oportunidad. Pero sí es conveniente recordar, siquiera sea grosso modo, los grandes bloques de cuestiones que constituyen normación básica o común a todo contrato de gestión de servicios públicos, cualquiera que sea su modalidad o la Administración que los tramite; porque la visión de ese tronco central nos podría llevar a la convicción de que es muy importante lo que se encuentra uniformado, cuantitativa ${ }^{10}$ y cualitativamente y que quizás la unidad de régimen de la concesión de servicio público está ya conseguida, que su función aglutinante ha alcanzado un nivel satisfactorio, y que sea obligado reconocer que la diversidad normativa que pueda surgir ya en el tramo de lo "no común" o parte entregada a la iniciativa de

\footnotetext{
${ }^{10}$ De su importancia cuantitativa resulta significativo el hecho de que la LCAP no siguió el método de hacer una nómina de sus preceptos básicos sino que invirtió el sistema, calificando en principio como básico todo el texto de la Ley salvo la lista de excepciones que figura en su Disposición Final Primera. La técnica empleada ha levantado reticencias en el ámbito autonómico, pues, ciertamente, no es "estéticamente" consonante con la significación que ha de tener lo "básico", como selección de la serie de normas que imponen un común denominador normativo. El Consejo de Estado ha criticado el uso de este método (Dictámenes núms. 1270/1993 de diciembre, 4464/1998 de 22 de diciembre, 3375/2001 de 5 diciembre). No obstante, el legislador estatal se ha mantenido en el uso de esta técnica, quizás por haber querido enfatizar la importancia de su competencia en esta materia, en línea con la doctrina del Tribunal Constitucional, y quizás también por una razón de carácter práctico dado que el número de preceptos "no básicos" de la Ley apenas alcanza el 10 por ciento del total. No obstante, es preciso reconocer que desde la pura perspectiva de la técnica jurídica este método de establecer lo básico mediante cláusula general o "a la gruesa" no resulta muy pulcro y crea problemas interpretativos en algunos casos.
} 
las Comunidades Autónomas es inexcusable y que, por tanto, debe abandonarse el esfuerzo de seguir recogiendo piezas sueltas de aquí y de allá para intentar verterlas en el gran saco de lo básico estatal.

Podemos decir, en efecto, que el cuerpo de lo básico es muy importante pues comprende los principios generales de la institución (la definición misma de la figura y sus modalidades; observancia de los principios de publicidad y concurrencia, igualdad y no discriminación; plazos máximos de duración, prohibición de la contratación verbal, etc.) ${ }^{11}$; el régimen de la preparación ${ }^{12}$ y adjudicación del contrato (tarifas; pliegos de cláusulas, publicidad de las licitaciones, régimen del concurso, requisitos de capacidad e idoneidad, prohibiciones de contratar, régimen de las garantías a prestar por

${ }^{11}$ Es básica: a) La determinación de que la figura ha de aplicarse a los supuestos de gestión indirecta de servicios públicos de contenido económico que los haga susceptibles de explotación por empresarios particulares, por no implicar ejercicio de la autoridad inherente a los poderes públi$\cos$; b) La exigencia de una previa declaración administrativa que explicite que la actividad de que se trata queda asumida por la Administración respectiva como propia de la misma (art. 155); c) Las modalidades del contrato de gestión de servicios públicos: Concesión, Gestión interesada, Concierto, Sociedad de economía mixta; d) La observancia de los principios de publicidad y concurrencia; así como los de igualdad y no discriminación; e) La sujeción del personal que intervenga en los procedimientos de contratación al deber general de inhibirse si está incurso en una causa de abstención; f) Principio general de que el objeto del contrato deberá ser determinado; g) Principio del precio cierto; h) Prohibición de su pago aplazado; i) Financiación adecuada al ritmo en que se produce la prestación; j) Principio de que la duración del contrato no puede ser perpetua o indefinida. Son básicos los plazos máximos de duración de los contratos, incluidas sus prórrogas; k) Principio de que la Administración no podrá contratar verbalmente, salvo que el contrato tenga carácter de emergencia; 1) La totalidad del régimen de la contratación en el extranjero.

12 Tiene carácter básico: a) la necesidad de formar un expediente en el que se justifique la necesidad del contrato, se precise el plazo de su duración y sus posibles prórrogas de manera expresa. Las tarifas a percibir de los usuarios, los procedimientos para la revisión del contrato y el canon que el concesionario hubiere de satisfacer, en su caso, a la Administración; b) el deber de aprobar, antes de la licitación (si la hay) o antes del perfeccionamiento del contrato, pliegos de cláusulas administrativas particulares que incluyan los pactos y condiciones definidoras de los derechos y obligaciones de las partes contratantes; así como el de facilitar copia de tales pliegos a los interesados que lo soliciten. Igualmente, tiene carácter básico el deber de elaborar pliegos de las prescripciones técnicas que hayan de regir la ejecución de la prestación, y sin que estas induzcan a restringir la libre competencia de empresas o productos; c) La regla de que los expedientes deben contemplar la totalidad del objeto del contrato, sin que este pueda fraccionarse para disminuir su cuantía. 
el contratista, etc) ${ }^{13}$. Asimismo, el régimen de los efectos del contrato (ejecución a riesgo y ventura del contratista, responsabilidad frente a terceros, prerrogativas administrativas, revisión de precios, invalidez de los contratos, cesión del contrato y subcontratación, etc.) ${ }^{14}$; y el régimen de su extinción

13 Es básico o común: a) Todo el régimen relativo a la publicidad de las licitaciones o convocatorias; y la presentación de las proposiciones de los interesados en contratar; b) La determinación de que los expedientes de contratación pueden ser ordinarios, urgentes o de emergencia; y algunos aspectos fundamentales del régimen de estos dos últimos; c) La previsión de que los contratos podrán llevarse a cabo por procedimiento abierto, restringido o negociado, así como las definiciones de estas tres modalidades. Igualmente, la previsión de que el concurso es la forma ordinaria de adjudicación; la regulación misma del concurso y el deber de la Administración de justificar -de motivar- la elección del procedimiento o forma de que se trate; d) Toda la regulación relativa a la acreditación por parte de los contratistas (sean nacionales o extranjeros) de su plena capacidad de obrar; la acreditación de su solvencia económica, financiera, y técnica o profesional (esto es básico a partir de la reforma de la LCAP de 1998); los medios o instrumentos mediante los cuales ha de acreditarse la solvencia, en esa triple vertiente; e) Es común para todos los contratos tanto la lista de prohibiciones para contratar (LCAP) en que pueden estar incursas las personas aspirantes, como el procedimiento para la declaración de tales prohibiciones; f) La regla de que son nulas de pleno derecho las adjudicaciones de contratos en personas carentes de capacidad de obrar o estén afectadas por alguna prohibición de contratar; g) Las reglas de que los contratos se perfeccionan mediante la adjudicación y que han de formalizarse en documento administrativo, sin perjuicio de su elevación a escritura pública cuando lo solicite el contratista; y la de que no se podrá iniciar la ejecución del contrato sin su previa formalización; h) La previsión de que la Administración pueda contratar con Uniones Temporales de Empresas, y sin que éstas necesiten formalizar la Unión hasta que se haya efectuado la adjudicación a su favor; i) En cuanto a las garantías exigibles al contratista, es básica la obligación de constituir fianza definitiva (bajo el régimen de cuantías establecido por la LCAP). Todo el régimen relativo a la constitución, reajuste, destino, cancelación, devolución, etc. de las garantías; así como la regla de que la no constitución de la garantía definitiva por causas imputables al adjudicatario determina la resolución del contrato.

${ }^{14}$ Son básicos: a) La regla de que el contratista está obligado a cumplir el contrato dentro del plazo total fijado para la realización del mismo, así como de los plazos parciales señalados para su ejecución sucesiva. b) El principio de que la ejecución del contrato se realizará a riesgo y ventura del contratista; c) En cuanto a los deberes del concesionario, es muy elemental la lista que establece la LCAP como reglas de carácter básico. Se trata sólo de obligaciones de carácter muy general (así, prestación del servicio con la continuidad convenida; apertura al público sin discriminación alguna; cuidar del buen orden del servicio...). Es comprensible la parquedad de esta regulación dado que las tablas de obligaciones y derechos de cada concesión se nutren de la normativa reguladora de cada servicio, muy dispar entre sí por la propia naturaleza de las cosas, y se plasman en los Pliegos de cláusulas particulares adheridas al contrato. d) La responsabilidad del contratista por los daños que cause a terceros, salvo que tales daños deriven de órdenes de la Administración; así como el procedimiento a seguir en estos casos. e) Es de suma importancia lo que concierne a las potestades que sobre la ejecución del contrato puede ejercer la Administración, siempre investida del privilegio de la ejecutividad de sus actos; así: Los poderes de policía "nece- 
(causas de resolución, reversión del servicio al término del plazo concesional, etc. ${ }^{15}$

Pero de cara a lo que aquí nos ocupa mayor interés tiene aún dejar constancia del "negativo" de la fotografía o lo "no básico", es decir, los huecos o vacíos que deja abiertos la legislación básica estatal ya que sobre ese vacío, cada una de las Comunidades Autónomas puede establecer una normación particular sobre contratos y concesiones dando lugar a un panorama normativo variopinto que podría ser muy perjudicial a la idea de unidad del sistema, si esas regulaciones autonómicas abordan cuestiones esenciales aunque no hayan sido consideradas "básicas" por el legislador estatal.

El legislador autonómico puede optar por una de estas tres soluciones: $a$ ) adoptar in totum la figura o regulación de que se trate, aunque no sea básica, bien repitiéndola al pié de la letra o remitiéndose pura y simplemente a la legislación del Estado; $b$ ) regular la misma figura o institución pero de manera diferente a como lo hace el Estado; c) no contemplarla en absoluto, creando una deliberada exclusión de la misma en el ámbito de la Comunidad Autónoma de que se trate. Dadas las variables indicadas, es ocioso advertir sobre la prudencia con la que debe obrar el legislador estatal a la hora de calificar co-

sarios" para asegurar la buena marcha de los servicios de que se trate; el "ius interpretationis", para resolver las dudas que ofrezca el cumplimiento del contrato; la potestad de acordar unilateralmente la resolución del contrato y determinar los efectos de aquélla. En cuanto al ejercicio del "ius variandi", la legislación estatal es ciertamente errática; consideraremos esta cuestión más adelante. g) Toda la regulación relativa al pago del precio y la transmisión de los derechos de cobro. h) El régimen de la invalidez de los contratos; las causas de nulidad y anulabilidad, su declaración y sus efectos. i) Buena parte del régimen de la revisión de precios: circunstancias que permiten la revisión, necesidad de que la fórmula de revisión conste en el Pliego de cláusulas administrativas particulares; h) La totalidad del régimen de la cesión de los contratos y la subcontratación; y que esta última sólo puede recaer sobre prestaciones accesorias.

15 Tienen carácter básico: a) Las causas de resolución de los contratos -con las puntualizaciones que haremos mas abajo- y sus efectos; el régimen de la aplicación de cada causa de resolución, salvo algunas previsiones para las causas de muerte o incapacidad sobrevenida del contratista; escisión, aportación o transmisión de empresas; situación de quita y espera y suspensión de pagos; b) La regla de que en los casos de resolución la Administración debe abonar al contratista el precio de las obras e instalaciones que este hubiese ejecutado y que hubiesen de pasar a propiedad de la Administración; c) La figura de la reversión del servicio a la Administración al término del plazo concesional y todo el régimen de cautelas que acompañan a este supuesto. 
mo "no básica" una determinada cuestión, dado el riesgo de que ello pueda generar una diversidad no razonable en una materia como ésta de tantas implicaciones jurídicas y económicas.

Pues bien, el conjunto de los preceptos que el Estado ha considerado como "no básicos", puede dividirse en tres categorías, según sea más o menos lógica o comprensible su exclusión del tronco común.

a) Un primer grupo de preceptos cuya calificación como no básicos es absolutamente lógica. Así, los alusivos a los órganos de la Administración del Estado, a sus atribuciones y a los mecanismos de relaciones entre ellos. Lógico es que la LCAP permita en este punto a las Comunidades Autónomas un ejercicio pleno de su potestad organizatoria. Así, la determinación de los órganos de contratación; la existencia o no de Mesas de contratación, o la de una Junta Consultiva de Contratación administrativa, etc.

Parece también razonable que no tenga carácter básico la posibilidad de elaborar pliegos de cláusulas administrativas generales, o establecer modelostipo de pliegos particulares de general aplicación a contratos de naturaleza análoga. Ni pliegos de prescripciones técnicas generales. También se comprende que el Estado no haya dado carácter básico a algunos procedimientos a realizar en el seno de la Administración contratante aunque tengan finalidad garantizadora, tales como los trámites internos a seguir para la modificación de los contratos (art. 101) o para acordar su suspensión (art. 102).

También es comprensible que no sea básica la posibilidad de que puedan fijarse garantías provisionales o definitivas a estimación del órgano de contratación en función de las circunstancias. Ni que sea básica la posibilidad de eximir al contratista de la constitución de garantías en casos especiales.

b) Un segundo grupo de preceptos puede englobarse bajo el rótulo de "soluciones discutibles", sobre las cuales es bien difícil dictaminar si su calificación como "no básicas" es o no acertada. Así, por ejemplo:

- La prohibición de contratar por haber sido sancionado el contratista en expediente administrativo en materia de subvenciones e infracciones tributarias.

- No es básica la regla de la responsabilidad solidaria ante la Administración de los miembros de las uniones temporales de empresarios, ni la del nombramiento de un apoderado único de la UTE. 
- La previsión de que en caso de muerte o incapacidad sobrevenida del contratista pueda la Administración acordar la continuación del contrato con sus herederos o sucesores.

- Las previsiones sobre la situación de demora del contratista, ni la posible alternativa de la Administración entre resolver el contrato o imponer penalidades, ni el régimen de éstas.

- Las consecuencias económicas derivadas del incumplimiento por la Administración de la entrega de contraprestaciones económicas y medios auxiliares a que se obligó en el contrato (art. 165).

- La posible intervención o secuestro del servicio por la Administración en caso de incumplimiento del contratista del que derive perturbación grave en el servicio público; así como la obligación del contratista de abonar a la Administración la indemnización de daños y perjuicios correspondiente (art. 166).

- Ciertas previsiones sobre la revisión de precios en caso de demora del contratista en la ejecución del contrato; y otros preceptos relativos al pago del importe de la revisión.

c) Por último, la calificación como "no básicos" de un tercer grupo de preceptos parece una solución más que discutible, por no decir chocante o incluso absurda en algún caso. Así, entre otros supuestos:

- No es básico que el expediente de contratación incorpore certificado de existencia de crédito, la fiscalización de la Intervención y la aprobación del gasto.

- Tampoco es básica la regla de que los expedientes calificados como urgentes tienen preferencia para su despacho.

- La LCAP (art. 155) afirma no ya el carácter no básico, sino que es inaplicable al contrato de servicio público el principio de que el contratista está obligado a cumplirlo dentro del plazo total fijado, así como de sus plazos parciales (art. 95.1) ${ }^{16}$.

${ }^{16} \mathrm{El}$ artículo 95 señala que el apartado 1 tiene carácter básico. Sin embargo, el artículo 155 declara no aplicable todo el artículo para los contratos de servicios públicos. 
- Tampoco considera aplicable al contrato de servicio público todo el artículo 96, expresivo de que la posible resolución unilateral decretada por la Administración por incumplimiento de estos deberes debe acordarse previa audiencia del interesado y dictamen del Consejo de Estado u órgano consultivo equivalente, amen de regular otros requisitos. Ello no deja al intérprete otra salida que la de hacer una interpretación razonable de esa exclusión del artículo 96 hecha por el legislador de un modo global y un tanto grosero y considerar que sí son aplicables los aspectos esenciales o básicos de ese artículo 96, es decir, la audiencia del interesado y el dictamen del Consejo de Estado u órgano consultivo equivalente de la Comunidad Autónoma respectiva $^{17}$.

- Mayor sorpresa, si cabe, es la que depara la decisión del legislador estatal de no atribuir carácter básico a la posibilidad misma de modificar las características del servicio contratado por razones de interés público y las tarifas que han de ser abonadas por los usuarios; ni el principio de que cuando las modificaciones afecten al régimen financiero del contrato la Administración debe compensar al contratista para que se mantenga el equilibrio correspondiente (art. 163).

Hay que señalar que la LCAP 13/1995 -redacción originaria- sí consideró básico lo que se acaba de exponer y que fue la reforma operada por la Ley 53/1999 la cambió el signo en este punto, abriendo a las Comunidades Autónomas la posibilidad de hacer lo que quisieran sobre el particular. Ello resulta absurdo y peligroso en un doble sentido, pues tan reprochable sería una Ley autonómica que no contemplara la posibilidad de modificar las características del servicio público contratado (lo que podría suponer grave quebranto para el interés público), como el supuesto contrario, es decir, que pu-

\footnotetext{
${ }^{17} \mathrm{Si}$ tomamos a rajatabla la inaplicabilidad in totum de ese artículo 96, como dice la LCAP, ello conduce a chocar absurdamente con lo dispuesto en el artículo 22 de la Ley Orgánica del Consejo de Estado. Este dice que la Comisión Permanente del Consejo de Estado deberá ser consultada en los expedientes de "nulidad, interpretación, modificación y extinción de concesiones administrativas, cualquiera que sea su objeto y cuando se formule oposición por parte del concesionario y, en todo caso, cuando así lo dispongan las normas aplicables". Por consiguiente, surge una frontal contradicción que afecta a las Comunidades Autónomas que no tienen establecido un órgano Consultivo propio y deben acudir por ello al dictamen del Consejo de Estado. Y también es palpable la incongruencia entre esa previsión de la LCAP y las Leyes autonómicas de creación de Órganos consultivos, que siguen en este punto el precedente de la LOCE.
} 
diera ser absolutamente permisiva con el ejercicio del "ius variandi" por cualquier motivo, pues tampoco se considera básica para el contrato de servicio público (art. 101) la regla, absolutamente consolidada y enriquecida por la doctrina del Tribunal Supremo y del Consejo de Estado de que el órgano de contratación sólo podrá introducir modificaciones por razones de interés público, siempre que sean debidas a necesidades nuevas o a causas técnicas imprevistas, justificándolo debidamente en el expediente.

Por último, no considerar básico, como hace la LCAP, el principio de que hay que compensar al contratista si la Administración altera unilateralmente las bases económicas del negocio es algo sorprendente que nos redime de hacer más comentarios al respecto. Y lo mismo cabe decir del hecho de que no sea básica la regla de que si la Administración suspende unilateralmente el contrato causando daño o perjuicio efectivo al contratista este tiene derecho a la indemnización correspondiente.

- La LCAP también excluye la aplicación del artículo 110 al contrato de servicio público. Es cierto que dicho artículo regula lo relativo al acto de recepción del objeto del contrato ya realizado y de la fijación del plazo de garantía a partir de la recepción o conformidad; y que su campo de aplicación es el de contratos que crean obligaciones de dar y no de hacer. Pero no es menos cierto que dicho artículo contiene en su apartado $1^{\circ}$ la regla de "el contrato se entenderá cumplido por el contratista cuando éste haya realizado, de acuerdo con los términos del mismo y a satisfacción de la Administración, la totalidad de su objeto"; y claro es que esta regla es susceptible de ser aplicada a cualquier contrato, por lo que la LCAP yerra claramente en este punto.

- Por último, hay que destacar el extraño tratamiento que da la LCAP a las causas de resolución. La Ley contempla un catálogo general de causas de resolución referibles a todo contrato administrativo de las cuales sólo 8 son aplicables a las concesiones de servicio público; más otro pequeño catálogo de cuatro causas específicas relativas sólo a estos contratos a las que, paradójicamente, la LCAP no les atribuye carácter básico. Estas son: a) demora de la Administración, superior a seis meses, en la entrega al contratista de la contraprestación o de los medios auxiliares a que se obligó; b) Rescate del servicio; c) Supresión del servicio por causa de interés público; d) Imposibilidad de la explotación del servicio como consecuencia de acuerdos adoptados por la Administración con posterioridad al contrato. Pues bien, la paradoja se acentúa a la vista de la relación de las causas de resolución que la propia Ley contempla para el contrato de concesión de obras públicas (art. 264) donde dichas cuatro causas aparecen con el ca- 
rácter de básicas. Es llamativa la incongruencia del legislador estatal en este punto y mucho más en relación con la figura del rescate del servicio por la Administración, ya que esta causa sí tenía carácter básico antes de la reforma de 1999, antes mencionada. Como indicamos al principio son los peligros de legislar "a parches".

2. El régimen del contrato de concesión de obras públicas: entre el uniformismo "vertical" y la disgregación "horizontal"

En esta ocasión no es nuestro cometido recordar los orígenes históricos de esta más que centenaria figura ${ }^{18}$, su contribución a la creación de las grandes infraestructuras del pasado, su papel decisivo en la construcción de las autopistas, ni las razones de su pujante reaparición, ya con carácter general, en el momento presente ${ }^{19}$. Digamos, en congruencia con el discurso que venimos exponiendo, que el régimen de esta figura contractual se mueve entre el uniformismo "vertical" y la disgregación "horizontal", como veremos enseguida.

A nuestros efectos importa es resaltar que el régimen de esta figura en la LCAP se contenía en cinco breves artículos (130 a 134) prácticamente simbólicos, y que a partir de la Ley 13/2003 ocupa todo un amplio Título, subdividido en Capítulos, del Texto Refundido ${ }^{20}$. Con esta operación dicho Texto Refundido acoge dos contratos típicos fundamentales: el ordinario de gestión de servicios públicos y el de concesión de obras públicas. Como sabemos, la propia Ley contiene unas disposiciones generales que ocupan todo su Libro I, que forman parte esencial del régimen de cualquier contrato administrativo típico.

Es fundamental destacar las siguientes notas:

\footnotetext{
${ }^{18}$ Sobre el origen y utilidad de esta figura para la construcción de las vías públicas, los "caminos de hierro" y los puertos son muy jugosas las consideraciones de COLMEIRO, M. Derecho Administrativo Español, 4ª edic. Madrid, 1876.

${ }^{19}$ En relación con la nueva regulación del contrato de concesión de obras públicas, vid. MAESE SECO, Luis F. "Comentarios a la Ley 13/2003, de 23 de mayo, del Contrato de Concesión de Obras Públicas”, en Justicia Administrativa, núm. 25, octubre 2004, edit. Lex Nova; y bibliografía en él citada.

${ }^{20}$ Título V del Libro II. Art. 220 a 266.
} 
a) La regulación del contrato de concesión de obras públicas estaba concebida para constituir una Ley independiente, y por ello se trata de un texto extenso, con visible vocación de autosuficiencia; o sea, no contiene sólo previsiones específicas o peculiares del contrato ${ }^{21}$ de concesión de obras públicas sino una regulación bastante completa de todo el contrato donde se repiten conceptos y soluciones del contrato de gestión de servicios públicos.

El Consejo de Estado criticó que se pretendiera hacer una Ley independiente $^{22}$, recomendando que el texto se insertara, "previa modificación" en la Ley general. Su criterio fue seguido pero no se procedió a una fusión o refundición de los preceptos nuevos y antiguos, como hubiera sido lo correcto, sino que simplemente se optó por yuxtaponer el nuevo texto mediante la adición de un Título al final de la Ley general ${ }^{23}$. De este modo, ni se ha hecho la Ley independiente prevista (en cuyo seno sí tenía algún sentido que contuviera preceptos de régimen jurídico general para darle a la Ley un cierto armazón), ni se ha hecho una refundición, como parecía obligado, a partir de la opción por incluir el nuevo texto en el cuerpo de la LCAP.

b) La segunda nota a retener es que el nuevo texto añadido a la Ley general está calificado casi en totalidad como de carácter básico, o sea, que el legislador estatal, en cuanto al contrato de concesión de obras públicas, ha robustecido la idea de lo básico estatal no dejando a las Comunidades Autónomas apenas margen de maniobra.

\footnotetext{
${ }^{21}$ Lo reconoce así la propia Exposición de Motivos de la Ley 13/2003: "De esta manera, la Ley de Contratos de las Administraciones Públicas se ve enriquecida con la regulación completa de este contrato, cuya utilización generalizada por las Administraciones públicas demandaba un régimen jurídico singularizado, atendiendo a sus características especiales, dentro del código de normas de contratación que constituye esta Ley”.

${ }^{22}$ Dictamen 3375/2001 de 5 de diciembre, Fto. V.1

${ }^{23}$ Así lo expresa la Exposición de Motivos de la Ley 13/2003: "Desde el punto de vista de la técnica normativa se ha optado por insertar la regulación específica de este contrato en la Ley de Contratos de las Administraciones Públicas, Texto Refundido aprobado por Real Decreto Legislativo 2/2000 de 16 de junio, siguiendo el criterio sostenido por el Consejo de Estado. En su virtud, se introduce, en la regulación de los distintos tipos de contratos administrativos del libro II, un nuevo título $V$ «Del contrato de concesión de obras públicas", que recoge el régimen jurídico de este contrato, ahora ya típico, atendiendo a las singularidades que presenta y en la línea de la tradición del derecho español. El resultado es un título armónico y sistemático en la medida que contiene una regulación de la concesión que, partiendo de la definición de la figura contractual, disciplina toda la vida del contrato en aquellos puntos en que realmente ha sido necesario su tratamiento singular respecto a la parte general del libro I de esta Ley". La afirmación que se hace en este último pasaje no responde a la realidad, como veremos más adelante.
} 
c) Por último hay que llamar vivamente la atención sobre el dato de que toda la regulación del contrato de concesión de obras públicas es de aplicación preferente y prevalece frente a cualquier norma contemplada en las Disposiciones generales (Libro I) del propio TR $\mathrm{LCAP}^{24}$ en cuyo texto está ubicado, como queda dicho, el nuevo régimen del contrato de concesión de obras públicas. Se da, por tanto, la paradoja, de que las normas de un contrato incluido como típico en la Ley general se sobreponen a las de la propia Ley general. Ello deja mucho que desear desde la perspectiva de la técnica jurídica, pues constituye algo más que un "parche", un gesto "técnico" del legislador realmente pintoresco.

Las observaciones anteriores nos permiten apreciar que, de cara al intento de unificar la figura de la concesión, la regulación actual del contrato de concesión de obras públicas se erige como un obstáculo, pero no en el sentido vertical que estamos ahora considerando (dado que prácticamente elimina la posibilidad de cualquier normación autonómica significativa), sino en sentido horizontal, habida cuenta los desajustes o fricciones que plantea con la propia normativa estatal, señaladamente la contenida en el resto de la LCAP.

Resulta muy difícil dictaminar si técnicamente hubiera sido posible incrustar o diluir la totalidad del capítulo $\mathrm{V}$ en el tejido de las normas generales de la LCAP y más concretamente en las que atañen a la concesión de servicios públicos. El hecho de que el contrato comprenda tanto la obra como su explotación (sea o no en calidad de un servicio público) genera dificultades de distinta índole ${ }^{25}$.

\footnotetext{
${ }^{24}$ Así resulta del nuevo artículo 7.2. de la LCAP, de gramática desafortunada, dicho sea de paso.

${ }^{25}$ De una parte, la dificultad estriba en que gran parte de la regulación del contrato de concesión de obras públicas está dedicado precisamente al régimen de la obra, y la supuesta tarea de incrustar ese cúmulo de preceptos en el contrato administrativo de obra no parece que sea cosa fácil o sencilla. De otra parte, el hecho de que el objeto del contrato de concesión de obras públicas consiste tanto en la construcción de la obra pública como su explotación, y de que esta explotación no tiene necesariamente que producirse mediante la gestión de un servicio público (que puede no existir) sino que puede consistir sencillamente en el uso y disfrute de la concesión demanial que se otorgue para la obra en cuestión. Por consiguiente, la figura de la concesión de obras públicas también se confunde en parte con la concesión demanial, y esto supone una dificultad añadida a la hora de postular un régimen unitario para la figura de la concesión administrativa de servicio público.
} 
En efecto, si hacemos una disección de los preceptos contenidos en ese Título $\mathrm{V}$ podemos clasificarlos en tres grupos:

a) Un primer grupo de preceptos que se refieren exclusivamente a la obra, y que son mayoría ${ }^{26}$. Es claro que una supuesta integración de estos preceptos en el contrato administrativo de obra hubiera sido una operación casi anti natura, dado que toda la regulación del contrato de obra está atravesada de la idea de que la realización de la obra y su entrega inmediata a la Administración es la prestación única y principal del contrato. Por tanto, aunque tanto en uno como en otro tipo de contrato existe siempre una obra ello no permite fusión jurídica alguna.

b) Un segundo grupo lo integran preceptos de un contenido mixto 27 pues en ellos se abordan, imbricadamente, tanto cuestiones relativas a la obra como a la explotación del servicio. Sería contrario a la técnica jurídica e incluso a la sensatez tratar de disgregar ambos aspectos con el fin de reubicarlos, respectivamente, bien en el contrato de obras o en el de gestión de servicios públicos. Sería como separar el alma del cuerpo.

c) Pero existe un tercer grupo de preceptos que abordan cuestiones generales o abstractas de puro régimen jurídico general. Este grupo de preceptos se solapa claramente con las disposiciones aplicables al contrato ordinario de gestión de servicios públicos. Se trata, pues de una zona secante en la que pueden contemplarse duplicadas las mismas instituciones o figuras. Y es en esta zona secante donde el legislador tendría que haber hecho el esfuerzo de fusionar el régimen jurídico y no crear un régimen paralelo, máxime cuando éste no iba a estar ya en una Ley independiente, como se proyectó en principio.

\footnotetext{
${ }^{26}$ Proyecto de construcción; conservación y reparación; zonas complementarias; estudio de viabilidad; financiación; replanteo; modalidades de ejecución; modificación del proyecto; terminación de las obras; uso de la obra; régimen económico y financiero; y un amplio capítulo dedicado a la financiación privada (emisión de títulos por el concesionario; hipoteca de la concesión; y otras fuentes de financiación).

27 Tienen este perfil de preceptos de contenido mixto los referidos al Anteproyecto de construcción y explotación de la obra, contenido de las proposiciones de los licitadores, contenido de los Pliegos de cláusulas administrativas particulares, derechos y obligaciones del concesionario, retribución por la utilización de la obra, y algunos otros más de ese híbrido corte.
} 
Creemos que hubiera sido posible, sin ningún forzamiento, suprimir de la regulación del contrato de concesión de obras públicas algunos contenidos, incrustándolos en las normas generales de la LCAP o en su Reglamento ejecutivo, si acaso con los matices que hubieran sido necesarios.

Así, no tiene sentido una regulación específica del contenido mínimo que han de contener los Pliegos de Cláusulas Administrativas particulares del contrato de concesión de obras públicas cuando esto es algo que el Reglamento de la LCAP resuelve al detalle, admitiendo cualquier especialidad que se le hubiera querido introducir. Y lo mismo cabe decir del régimen de la convocatoria de licitación, de los requisitos exigidos a los licitadores, del régimen de las proposiciones, procedimientos y formas de adjudicación del contrato, plazos de las concesiones. Y también lo relativo al mantenimiento del equilibrio económico del contrato, máxime teniendo en cuenta las matizaciones que el legislador del contrato de concesión de obras públicas ha introducido en el sentido de que el equilibrio deberá restablecerse tanto si se rompe en perjuicio como a favor del concesionario, previsión esta razonable que no se entiende por qué haya de ser privativa del contrato de concesión de obras públicas.

Y, desde luego, hubiera sido no sólo factible sino absolutamente conveniente la unificación del régimen de las prerrogativas administrativas en la ejecución de los contratos ya que aquí se detectan llamativas contradicciones entre uno y otro régimen, sobre todo en lo tocante a la calificación o no de carácter básico a prerrogativas idénticas. Así, las potestades administrativas para modificar los contratos, para acordar la intervención o secuestro de la concesión, o para imponer al concesionario penalidades en caso de incumplimiento, sí son consideradas como básicas en el contrato de concesión de obras públicas, sin que se vea cual sea la razón que justifique estas discordancias entre ambos regímenes, máxime tratándose de algo tan delicado, en términos constitucionales y políticos, como la determinación de lo que es básico estatal.

Y análogas discordancias se aprecian, esta vez en más y en menos, en lo referente a las causas de resolución, su aplicación y sus efectos. Ya dijimos anteriormente cómo el régimen del contrato de concesión de obras públicas considera básicas cuatro causas de resolución que no tienen esa condición en las normas del contrato de gestión de servicios públicos. Contrariamente, tampoco se entiende cómo en la nutrida lista de causas de resolución del contrato de concesión de obras públicas -en la que se repiten los supuestos contemplados en el régimen general- estén ausentes sin embargo dos de ellos: la falta de prestación de las garantías definitiva, especiales o complementarias y la no formalización del contrato en plazo. Cierto es que en lo no regulado por 
las normas del contrato de concesión de obras públicas pueden ser aplicables las del régimen general, cubriendo así sus lagunas, pero no hay que ser muy sagaz para saber que esos desencajes legales son en la práctica fuente de problemas que el legislador tendría que evitar de antemano.

\section{B. LA LEGISLACIÓN AUTONÓMICA}

\section{Legislación general de desarrollo de las bases estatales}

Los Estatutos de Autonomía utilizan una fórmula prácticamente uniforme para definir la competencia en esta materia: "desarrollo legislativo y ejecución de la legislación básica del estado en materia de contratos y concesiones administrativas en el ámbito de las competencias propias de la Comunidad Autónoma”. Cabe, por tanto, preguntarse cuál ha sido la ejecutoria de las Comunidades Autónomas en este campo, cómo han ejercitado sus competencias de desarrollo legislativo.

La legislación autonómica en estas materias puede surgir por dos vías, bien mediante el desarrollo puro y simple de las bases estatales contenidas en la LCAP, dotando a la Comunidad Autónoma de una regulación abstracta y genérica sobre contratos y concesiones administrativas, al igual que lo hace la LCAP; o bien introduciendo ese desarrollo normativo en la regulación particular y concreta de cada servicio público de su competencia. Ocioso es decir que esa labor de desarrollo, sea genérica o sea particular, puede hacerla mediante leyes o reglamentos.

Por consiguiente, para hacer una evaluación precisa del uso que han hecho las Comunidades Autónomas de sus competencias en esta materia sería menester tener a la vista las disposiciones de cualquier rango que organizan y regulan cada servicio público, y puede afirmarse que son numerosísimas. No obstante, el dato de la cantidad de disposiciones no es lo fundamental, sino si estas disposiciones introducen verdaderos desarrollos normativos de la legislación básica del Estado o se limitan a reiterar esta legislación o remitirse a ella.

Todo apunta a esta segunda hipótesis, es decir, que el grado de innovación de las normas autonómicas en esta materia es prácticamente inexistente. Este es un indicio seguro que se obtiene a la luz de lo que ofrecen las muy escasas normas con rango de ley surgidas de los parlamentos autonómicos.

En efecto, de entrada hay que destacar que ninguna Comunidad Autónoma ha dictado una Ley específica para el desarrollo de las bases estatales en 
materia contractual, ello salvo el Parlamento de Navarra con su Ley Foral 10/1998 de 16 de junio, Ley extensa que obedece a la situación especial de esa Comunidad Autónoma ya que en virtud de su régimen foral ostenta competencia exclusiva sobre contratos y concesiones administrativas respetando los principios esenciales de la legislación del Estado en la materia. Pues bien, sin poder detenernos aquí en hacer un cotejo entre los preceptos de esta Ley foral y los de la LCAP, sí podemos afirmar que al menos en lo que atañe al contrato de gestión de servicios públicos guardan una semejanza casi absoluta, ofreciendo como diferencia más llamativa que las concesiones de la competencia de Navarra pueden tener una duración de hasta 75 años siendo así que las de Derecho común no pueden exceder de 25 si sólo implican explotación del servicio.

Por lo demás, el panorama de leyes autonómicas que abordan en abstracto el desarrollo legislativo de la materia contractual queda limitado a algunas leyes autonómicas reguladoras del Gobierno y la Administración de la Comunidad Autónoma. Estas incorporan algunos preceptos en materia de contratos, generalmente muy escasos, dedicados bien a desarrollar las bases estatales, o bien a incorporar o asumir análogos preceptos contenidos en la LCAP que no tienen el carácter de normación básica. Tal es el caso de las Leyes del Gobierno y la Administración de las Comunidades Autónomas de Principado de Asturias' Islas Baleares, Cantabria, Castilla y León, Madrid, Murcia y La Rioja ${ }^{28}$. En términos generales puede afirmarse que estas leyes se limitan a introducir normas organizatorias del corte de las previstas para la Administración del Estado en la LCAP; así, las que definen los órganos de contratación y sus competencias, o establecen Mesas de contratación, o una Junta Consultiva de Contratación Administrativa o un Registro de Contratos; o bien el lugar donde han de depositarse las fianzas; o mandan que se elaboren Pliegos de Cláusulas generales; o simplemente se limitan a recordar las prerrogativas administrativas en la ejecución de los contratos. Como se ve, ninguna norma de desarrollo proprio sensu. Por excepción puede citarse la previsión del artículo 146 de la Ley de Cantabria reservando a su Gobierno la posibilidad de disminuir las cuantías fijadas por la legislación estatal para considerar los contratos

\footnotetext{
${ }^{28}$ Principado de Asturias, Ley 2/1995 de 13 de marzo (Art. 36 a 41). Islas Baleares, Ley 3/2003 de 26 de marzo (Art. 63 a 66). Cantabria, Ley 6/2002 de 10 de diciembre (Art. 141 a 153). Castilla y León, Ley 3/2001 de 3 de julio (Art. 77 a 79). Madrid, Ley 1/1983 de 13 de diciembre (Art. 62 a 68). Murcia, Ley 1/1998 de 7 de enero (art. 63). La Rioja, Ley 3/1995 de 8 de marzo (Art. 109 a 114).
} 
como menores, previsión está que sí tiene naturaleza de norma de desarrollo. Esta excepción, de escasa envergadura, viene a resaltar la regla de que el panorama del derecho autonómico en esta materia tiene un nivel muy modesto y es absolutamente pacífico. Por tanto, la uniformidad de la concesión no se resiente desde esta perspectiva "vertical". Pero se trata de una estabilidad precaria, siempre expuesta a un posible cambio.

\section{La legislación sectorial reguladora de los distintos servicios públicos}

Las leyes autonómicas reguladoras de servicios públicos concretos presentan el mimetismo ya proverbial que ha venido a asentarse en la normativa de las autonomías, y el elenco de servicios públicos objeto de regulación no se caracteriza precisamente por su variedad.

Esta legislación autonómica sectorial es realmente la que permite deducir cual sea el nivel de uniformidad o de disgregación que presente la abstracta figura de la concesión en esta vertiente "vertical" que estamos considerando, pues si bien puede decirse que a las Comunidades Autónomas no les queda mucho espacio para desenvolver sus competencias de desarrollo legislativo en el ámbito del título "contratos y concesiones administrativas" ex art. 149.1.18 CE (lo que en buena medida queda corroborado por la legislación aparecida hasta ahora, según vimos en el epígrafe anterior), sí disponen en cambio de un margen mucho mayor para regular los servicios concretos, máxime cuando aquí viene a incidir con especial intensidad la potestad organizatoria.

Las normas relativas a estos servicios no son sino la expresión del ejercicio de competencias sectoriales asumidas, por lo que habrá que estar en cada caso a la regla de reparto que corresponda; y en este sentido hay que señalar que en la mayoría de los casos las competencias de las Comunidades Autónomas para la regulación y gestión de esos servicios o materias tienen el carácter de exclusivas. En cualquier caso, por reducida que sea la competencia autonómica para regular algún sector determinado, la mera tenencia de una competencia de carácter ejecutivo o de gestión siempre abrirá la puerta de entrada a su potestad natural para disciplinar los servicios públicos mismos, y a la de incluir particularidades de tipo organizativo que a la postre acabarán modulando el régimen de la concesión de que se trate.

Ciertamente, hay que partir del principio de que por más amplia que sea la competencia que se ostente en relación con un servicio determinado, el ejercicio de ésta nunca podrá llegar a conculcar ningún precepto calificado por el Estado como básico en materia de "contratos y concesiones administra- 
tivas", ni nada que competa al Estado en el ámbito de lo sectorial. Pero sentado esto, no cabe desconocer la considerable incidencia que puede tener la regulación de cada servicio en el régimen jurídico del contrato mediante el cual el servicio se concede, de modo que sin atacar en lo más mínimo las bases estatales, la regulación de cada servicio será la que introduzca las particularidades sobre cómo deba ser prestado, requisitos que deben reunir los concesionarios, criterios de adjudicación, deberes del concesionario, duración de la concesión, condiciones de explotación, causas de extinción..., todo lo cual imprime a cada clase de concesión un perfil propio y singularizado que conduce a una diversidad que ha de estimarse absolutamente lógica y consecuente con la naturaleza de las cosas. Por ello, cualquier pretensión de unificar para todas las concesiones estos aspectos "secundarios" pero tan determinantes del modo de ser de cada concesión carecería de sentido. En este terreno las especialidades están plenamente justificadas y postular lo contrario sería forzar la realidad para, al cabo, obtener un resultado artificioso e inútil.

El legislador autonómico se ha centrado especialmente en regular los servicios de emisoras de radiodifusión sonora ${ }^{29}$ y de televisión local por ondas terrestres $^{30}$, cuyos regímenes nos muestran esas importantes peculiaridades que en último término se plasman en el contrato concesional pero que no constituyen propiamente "desviaciones" respecto de un supuesto modelo "ortodoxo" de concesión, sino determinaciones específicas absolutamente congruentes con las características del servicio. Otros servicios públicos también regulados por leyes autonómicas confirman, como no podía ser de otro modo, lo que se acaba de exponer ${ }^{31}$. Mención especial merece el Decreto 347/2002 de 19 de noviembre, Reglamento de Bienes, Actividades, Servicios y Obras de las Entidades Locales de Aragón, disposición situada fielmente en la doble virtud que ha de presidir la ordenación de cada servicio público concreto: de una

\footnotetext{
${ }^{29}$ Así, las Leyes de las Comunidades Autónomas de Andalucía, Aragón, Canarias, Castilla y León, Comunidad Valenciana, Galicia, Madrid, Murcia, País Vasco.

${ }^{30}$ Leyes de las Comunidades Autónomas de Andalucía, Castilla-La Mancha, Cataluña, Navarra.

${ }^{31}$ Así, Leyes autonómicas sobre transporte público urbano por carretera (Navarra, explotación de carretera (Madrid), transporte marítimo de viajeros (Galicia), gestión de residuos industriales (Galicia, Cataluña). Esta última Comunidad ha sido la que más servicios ha regulado mediante Ley. Aparte de los ya mencionados: concesión portuaria, explotación de ciertas líneas del ferrocarril metropolitano de Barcelona, transporte público por cable.
} 
parte, el respeto a la legislación básica estatal sobre contratos, a la que dicho Reglamento se remite constantemente; pero por otra parte contempla una larga lista de potestades que la Entidad local habrá de ir escogiendo en función de la clase de concesión a perfilar. ${ }^{32}$

\section{EL CONDICIONANTE "HORIZONTAL", DERIVADO DE LA DIVERSIDAD DE TIPOS CONCESIONALES}

En este punto nos referimos a las dificultades que de cara a la idea de la unificación de la figura de la concesión plantea el hecho de la existencia de tipos muy diversos de contratos concesionales. Como ya quedó advertido no estamos aquí ante un condicionante de carácter político, o sea, constitucional o "vertical", sino puramente técnico ya que, al menos en hipótesis, quedaría en manos del legislador estatal la posibilidad de acometer una presunta un unificación del régimen de la concesión Ahora bien, ocioso es insistir en que tratar de fusionar lo que no es fusionable es empeño vano, amen de nocivo.

Señalamos a continuación los factores que inciden en este plano "horizontal" formado por las leyes especiales del Estado.

\section{A. EL DOBLE EFECTO DISGREGADOR-UNIFICADOR DEL NUEVO RÉGIMEN DEL CONTRATO DE CONCESIÓN DE OBRAS PÚBLICAS}

Ya quedó resaltada más arriba la fuerza unificadora del régimen del nuevo régimen del contrato de concesión de obras públicas en la vertiente "vertical" por estar compuesto casi en su totalidad de normas calificadas como básicas, logrando así un "común denominador normativo" a respetar en el futuro por las Comunidades Autónomas. Y también su efecto disgregador en el plano horizontal dada la superposición de sus normas sobre el preexistente contrato de gestión de servicios públicos en aspectos que podrían haber quedado refundidos o regulados en los mismos preceptos.

\footnotetext{
${ }^{32}$ Son, pues, aspectos a precisar los relativos a la modificación del contrato, fiscalización de la gestión del concesionario, asunción temporal del servicio por la Administración, sanciones, rescate, supresión del servicio, extinción y resolución del contrato, retribución del concesionario, derechos y deberes.
} 
Pero también hay que señalar su efecto unificador en este último plano, dado que la Ley 13/2003 ha atraído para sí la regulación de algunos contratos de concesión de obras públicas antes regulados por leyes específicas.

Así sucede en relación con el contrato de concesión de construcción y explotación de autopistas. Este se regía en primer lugar por lo dispuesto en su Ley reguladora, 8/1992 de 10 de mayo de Construcción, conservación y explotación de Autopistas, y subsidiariamente por la LCAP. La Ley 13/2003 ha invertido la prelación estableciendo como derecho preferente el del contrato de concesión de obras públicas ${ }^{33}$.

Hay que notar que el nuevo régimen del contrato de concesión de obras públicas no viene a sustituir por entero al que se hallaba regulado en la Ley de Autopistas, dejando subsistentes no pocos preceptos de esta. Pero es fundamental al respecto la Disposición derogatoria única de la Ley 13/2003 que con evidente buen criterio enumera los artículos de la Ley de Autopistas ${ }^{34}$ que quedan derogados, con lo cual evita la confusión que hubiese podido crear la superposición de regímenes de haber abandonado al juicio del intérprete la determinación de los preceptos aplicables en cada caso.

Como queda dicho, la Ley 13/2003 deja en vigor otra serie de preceptos de la Ley de Autopistas de los que puede decirse, en términos generales que lejos de colisionar con el régimen general de la concesión de obras públicas, constituyen el conjunto de particularidades que son propias de "una concesión de autopistas", razón por la que no resultan absorbibles por unas normas que pretenden ser el derecho común de las concesiones.

33 Así lo dispuso la Disposición adicional 8ª 1 de la Ley 13/2003, dando una nueva redacción al artículo 2 de la Ley de Autopistas en el sentido indicado. Así, este artículo establece ahora que "Las concesiones a que hace referencia el artículo anterior se regirán por lo previsto para el contrato de concesión de obras públicas en la Ley de Contratos de las Administraciones Públicas, en los términos previstos en su artículo 7, y por lo previsto en esta Ley".

${ }^{34}$ Así, los requisitos para tener la condición de adjudicatario (art. 8); fianza definitiva (art. 9); beneficios tributarios (art. 11); expropiación forzosa y limitaciones a la propiedad privada -que no constituyen propiamente aspectos del régimen del contrato sino disposiciones paralelas que son inherentes al tipo de actividad de que se trata- (arts. 16 a 20); potestades de la Administración -centradas en el régimen de imposición de penalidades y en el ius variandi- (arts. 21 a 25); algunos deberes específicos de los titulares de estas concesiones (arts. 28 y 29); y algunas previsiones específicas referidas a la cesión del contrato (art. 31), suspensión temporal de la concesión (art. 33) y su extinción (art. 35). 
Mayor presencia alcanza aún el régimen instaurado por la Ley 13/2003 en relación con el contrato de concesión de obras hidráulicas pues en este caso la técnica empleada ha sido la supresión pura y simple del régimen de esta concesión que se hallaba contemplado en el TR de la Ley de Aguas (RD. Legislativo 1/2001 de 20 de julio). Por consiguiente, es aplicable in totum el nuevo régimen general del contrato de concesión de obras públicas, sin perjuicio de las especialidades, muy escasas, que la propia Ley 13/2003 recupera para su reinserción en el propio cuerpo de la Ley de Aguas, especialidades referidas al plazo de la concesión (establecido en un máximo de 75 años) y un par de cláusulas a incluir en los Pliegos de condiciones administrativas particulares.

Por último, la influencia del nuevo régimen del contrato de concesión de obras públicas se deja ver en la nueva Ley 39/2003 de 17 de noviembre del Sector Ferroviario. En este caso, es la propia ley especial de ferrocarriles la que se remite a lo dispuesto en la LCAP en relación con los contratos a celebrar por el administrador de infraestructuras ferroviarias para la construcción y administración de estas infraestructuras, "con las especificaciones contenidas en la presente Ley" (art. 22.5.).

Respecto a la actividad de transporte ferroviario, este se presta en régimen de libre competencia por lo que las empresas ferroviarias han de proveerse de una autorización o "licencia de empresa ferroviaria" (art. 44), que queda absolutamente al margen del régimen contractual de la LCAP.

Los ejemplos anteriores ponen de relieve el papel del nuevo régimen del contrato de concesión de obras públicas como centro de absorción y eliminación de regímenes especiales dispersos, lo que avala esa su condición de régimen aglutinante o unificador que destacamos al principio.

\section{B. LAS LEYES ESPECIALES QUE REGULAN SERVICIOS PÚBLICOS CONCRETOS. ¿ES ANÓMALA ESTA DIVERSIDAD?}

Es un hecho que existen leyes reguladoras de servicios públicos concretos que aún siguen siendo servicios públicos en el sentido clásico; y creemos que nunca dejarán de existir tales leyes. Es más, mientras más rígido o imperativo sea el derecho común que queramos constituir más necesarias serán en tal caso las leyes especiales.

El problema, de cara a una pretendida unificación del régimen de la concesión, no es que estas leyes existan, ni incluso el hecho de que puedan ser nu- 
merosas o que presenten un denso contenido. En realidad, las normas contenidas en esas leyes especiales no deben abordar cuestiones de régimen contractual puro -aunque de hecho los aborden, lo que será una mera cuestión de auto-indisciplina-, sino particularidades referidas al servicio. Este es el sentido del artículo 154 de la LCAP, al decir que "los contratos... de gestión de un servicio público, se regularan por la presente Ley y por las disposiciones especiales del respectivo servicio”.

De lo anterior se sigue que las disposiciones que regulan los servicios públicos concretos no son propiamente "leyes especiales", sino leyes particulares que deben atender exclusivamente a las singularidades del servicio de que se trate, sin violentar por ello el régimen común contemplado en la LCAP. No se da, pues, la relación Ley general-lex specialis; porque la norma referida al servicio no debe estar concebida para derogar, desplazar o prevalecer sobre la Ley general.

Un examen de las normas reguladoras de estos servicios nos permite comprobar que esto es así, al menos tendencialmente. Así resulta, por ejemplo, de la Ley de Navegación Aérea de 21 de julio de 1960, Ley que establece numerosos deberes y requisitos relativos al servicio (que, lógicamente, miran en este caso a la seguridad) y que han de plasmarse en el clausulado de la concesión $^{35}$. Lo mismo cabe decir de la Ley 13/1998 de 4 de mayo de Ordenación del mercado de Tabacos, con sus singularidades previstas para el logro de sus particulares objetivos que no son otros en este caso que la transparencia y la libre concurrencia entre aspirantes, singularidades que nutren los Pliegos y perfilan el status del concesionario, así como las causas de resolución o revocación. Y lo dicho es extensible a otras leyes reguladoras de servicios; así, la primitiva Ley de Autopistas de Peaje, e incluso leyes referidas a actividades liberalizadas que se valen ocasionalmente del contrato concesional.

En conclusión, todas las desviaciones del régimen común que pudieran encontrarse en esas mal llamadas "leyes especiales" -y de hecho las hay- no son sino patologías del sistema, no consecuencias normales o inherentes del sistema mismo.

\footnotetext{
${ }^{35}$ Clasificación de las aeronaves, documentos de a bordo, registro de matrícula, certificados de aeronavegabilidad, de los aeropuertos y aeródromos, personal aeronáutico, tráfico aéreo, responsabilidades, seguros, etc.
} 


\section{C. ¿ES FACTIBLE UN RÉGIMEN UNIFICADO PARA LA CONCESIÓN DEMANIAL Y LA DE SERVICIO PÚBLICO?}

No favorecería en nada al propósito que aquí nos ocupa ponerse de entrada a considerar una vez más las diferencias de naturaleza que tradicionalmente se predican de la concesión demanial y la de servicio público, pues ello significaría levantar un muro de separación apriorístico entre ambas instituciones, lo que impediría proseguir en esta tarea, de alcance puramente pragmático, consistente en detectar afinidades de una y otra institución que pudieran en su caso hacer posible la unificación de su régimen jurídico; ello sin tratar de violentar su respectiva identidad y naturaleza jurídica.

De esas diferencias ha dado buena cuenta la doctrina y la jurisprudencia, cifrándolas básicamente en el dato del carácter unilateral de la concesión demanial -con la correlativa presencia de una mayor discrecionalidad de la Administración-, y el carácter bilateral o contractual de la de servicio público ${ }^{36}$. Pero ni siquiera estos rasgos son indiscutibles, tanto por la factura bilateral que ofrecen muchas concesiones demaniales como por la también controvertible afirmación de que el concierto de voluntades que se produce en la contratación administrativa configure un verdadero negocio bilateral ${ }^{37}$. Son discutibles las dos cosas; aquí lo importante no es la forma o "cáscara", sino el grano. Por todo ello parece preferible abandonar tales cuestiones dogmáticas para centrarnos en las similitudes y diferencias reales que ofrecen ambas figuras en el plano puramente operativo de su funcionamiento práctico, aun siendo conscientes de que el régimen jurídico de cualquier institución no es algo ajeno a la naturaleza jurídica de la misma ni, por tanto, a los principios ínsitos en ella, sino más bien la proyección normativa de ese modo de ser.

En el plano del derecho positivo, es obligado citar el punto de encuentro entre ambas instituciones representado por el art. 62 del antiguo Reglamento de Bienes de las entidades locales de 1955 -reproducido en el artículo 78.2 del

${ }^{36}$ Vid., entre otras, SSTS de 12 abril 1985 (Ar. 2204) y 5 diciembre 1990 (Ar. 9631).

${ }^{37}$ Vid. sobre este último punto MARTÍNEZ LÓPEZ-MUÑIZ, J.L., quien propugna la tesis de la naturaleza jurídica unilateral que tiene en su origen todo contrato público, "Naturaleza de los contratos públicos a la luz del Derecho español, su fundamento y sus consecuencias", en la obra colectiva en homenaje al profesor Miguel S. Marienhoff, dirigida por Juan Carlos Cassagne, Derecho Administrativo, Abeledo-Perrot, 1998, págs. 947 a 969. 
vigente Reglamento de Bienes de las Entidades Locales de 13 de junio de 1986-, al señalar que "las concesiones -demaniales- se otorgarán previa licitación, con arreglo a los artículos siguientes y a la normativa reguladora de la Contratación de las Corporaciones Locales", remisión a las normas contractuales que repite en el artículo 81, si bien éste, con mayor precisión, se refiere a las "formalidades". También la moderna Ley de Patrimonio de las Administraciones Públicas (Ley 33/2003 de 3 de noviembre) hace remisión a algunos preceptos de la Ley de contratos relacionados con los llamados "actos separables".

Por tanto, la legislación de bienes remite a las "formalidades" o a la fase de "licitación" que se contempla en la normativa contractual. Hay que reconocer, pues, que ello representa una convergencia, un importante punto de encuentro entre ambos tipos de concesiones (órganos competentes para contratar; lista de prohibiciones que recaen por igual sobre contratistas y concesionarios demaniales; otorgamiento en régimen de concurrencia, mediante concurso por lo general; incluso la necesidad de formalizar la concesión y su posible inscripción en el Registro de la Propiedad.

Pero estos aspectos coincidentes no deben oscurecer la visión de las notables diferencias que se abren entre ambas instituciones incluso en la fase preparatoria de los respectivos procedimientos; así, en cuanto a la formación de los expedientes, publicidad de las licitaciones o convocatorias, acreditación de la solvencia económica y financiera, régimen de garantías, y demás diferencias ligadas al hecho de que la concesión demanial es ante todo un procedimiento generalmente iniciado a instancia de parte por el que el concesionario adquiere un derecho real sobre la cosa para su uso privativo, no para prestar un servicio a terceros, aunque a veces esta prestación vaya aneja si bien en virtud de otro título, distinto al puramente demanial.

Por tanto, a pesar de las apariencias, es muy débil la conexión existente entre ambos tipos de concesiones incluso en el plano de las formalidades previas. Pero si nos fijamos en el plano sustantivo o de la vida de la concesión ya otorgada la conexión es prácticamente nula. En este plano sustantivo es donde se erigen las diferencias de naturaleza entre la concesión demanial y la de servicio público, la de acto unilateral de una y la de pacto bilateral de otra, por más que en ambos casos se haya seguido análogo "iter" para su otorgamiento.

Ciertamente, la Administración habrá de cuidar porque la concesión demanial a otorgar se conceda a quien mejor garantice que será útil y provechosa para la economía y los intereses generales; y estará igualmente interesada en 
el buen uso o aprovechamiento del bien que ha de serle devuelto en su día. Pero no existe un interesamiento inmediato sobre la ventura o desventura de la explotación misma; y esta nota tiñe todo el régimen jurídico de la concesión demanial de un color absolutamente distinto del que es propio de la concesión de servicio público, ya que en este caso la Administración, como dominus del servicio, viene obligada de continuo a velar por la buena marcha de su gestión.

Así, no están presentes en el régimen de la concesión demanial instituciones claves que constituyen la esencia de la concesión de servicio público, tales como la obligación de apertura al público y el régimen tarifario, el mantenimiento de la ecuación financiera del contrato y el ejercicio de las prerrogativas administrativas en la ejecución de los contratos, reducidas en este caso a una facultad de inspección de la Administración concedente en garantía de que el bien es usado de acuerdo con los términos de la concesión. Bastaría también cotejar las causas que dan lugar a la extinción de los contratos y concesiones demaniales para desistir de todo empeño de fusionar sus respectivas regulaciones.

La conclusión que se desprende de lo expuesto es que hay puntos de encuentro o similitud entre las concesiones demaniales y las de servicio público pero son más los aspectos que las separan.

\section{UNA PREMISA FUNDAMENTAL: QUÉ DEBA ENTENDERSE POR "RÉGIMEN JURÍDICO GLOBAL"}

Pero volvamos a la pregunta inicial: "¿régimen jurídico global o pluralidad de regímenes especiales....?”. Es realmente decisivo despejar qué queramos decir por "régimen jurídico global", pues caben en principio tres interpretaciones o hipótesis:

a) Si por "régimen global" se quiere decir "derecho común", único y universal, imperativo para toda concesión de cualquier clase (así, para una concesión de línea aérea, un concierto sanitario o para instalar un servicio de hamacas en la playa), habría que desechar la idea, ya que supondría un retroceso respecto de la situación de partida o actual. Si hemos de convenir -de acuerdo con la teoría general del derecho- que el derecho común es absolutamente indesplazable e inatacable, habría que "adelgazar" ese derecho común hasta dejarlo con mucho menos peso del que hoy tiene la concesión de gestión de servicios públicos regulada en la LCAP. Por tanto, habría que reducirlo prácticamente a un ramillete de principios y a una colección de reglas principales relativas a la preparación y adjudicación de los contratos -que constituirían realmente el único cuerpo unificable de carácter común, y no sin 
excluir de él algunas reglas-, prerrogativas administrativas, causas de invalidez... y poco más. Cabe preguntarse si éste es el resultado que se quiere cuando se habla de unificación de la figura concesional en relación con las reglas dimanantes del Derecho comunitario pues ya vemos que tal resultado es poco mollar.

Más desechable aún sería la idea de un "régimen global" como equivalente a "Derecho general", pues este presupone la existencia de verdaderas "leyes especiales" llamadas a desplazar y prevalecer sobre la ley general. En suma, no tendría sentido crear una Ley general que recopilase todas las variables que ofrecen los regímenes de los servicios públicos concretos; o sea, una ley comprensiva del elenco de problemas y soluciones que podrían darse en cualquier concesión y que por tanto valiese para todas ellas en general y para ninguna en particular. Tal sería una falsa Ley unificadora, sin fuerza ordenadora per se para disciplinar una concesión concreta; en suma, no pasaría de ser un texto comprensivo de un extenso catálogo de hipótesis (requisitos a reunir por los concesionarios, derechos y deberes, causas de resolución o de extinción, etc.), quizás ilustrativo en el plano docente, pero de nula eficacia ordenadora.

La tercera hipótesis es que por "régimen global" se entienda no un tipo de Ley abstracta -común o general, como en las hipótesis anteriores- sino una Ley reguladora de la figura típica por excelencia, que sería la cabecera de todo el sistema (como lo fue el contrato de obras antes de la Ley de Contratos de 1995). Una Ley no directiva sino operativa, válida para regir directamente una concesión, pero que a su vez contuviese preceptos flexibles capaces de disciplinar cuestiones de régimen jurídico propias de servicios públicos concretos o especiales. Este tipo de normación tendría que tomar como objeto el contrato de concesión de obras públicas que sería el llamado a absorber el régimen de la concesión simple u ordinaria de gestión de servicios públicos, produciendo así una especie de accesión invertida. Otra alternativa sería la de crear un verdadero régimen común a los dos tipos concesionales, aunque dejando a salvo sus respectivas particularidades pues siempre habrá de tenerse en cuenta que son tipos distintos.

En todo caso, de cara al presunto propósito de unificar el régimen de la concesión al máximo posible, la referencia habría de ser el contrato de concesión de obras públicas; y ello porque la dimensión de lo que regula es mayor; porque su fuerza de penetración vertical -no discutida por las Comunidades Autónomas- es superior a la del contrato de gestión de servicio público; y por su superior expansividad en el plano horizontal, dada la propagación de la fi- 
gura como instrumento idóneo, en los tiempos que corren, para la construcción y gestión de grandes obras y servicios públicos.

A nuestro juicio poco más se podría hacer de cara a una supuesta unificación de la institución concesional. Lógicamente, otra alternativa sería dejar las cosas tal como están ya que se encuentran en paz. Quizás sea lo aconsejable en evitación de que hubiera que dar la razón a la conocida Ley de Murphy según la cual toda situación es susceptible de empeorar.

Sevilla, noviembre de 2004 